\title{
A LETRA E O MITO \\ Contribuições de Pau Brasil para a consagração bandeirante nos anos de 1920*
}

\section{Ana Lúcia Teixeira}

Para Paulo

Pau Brasil tem início em um gesto de negação da história do Brasil precedente à sua publicação. Seu mote inicial, que, apesar de breve, é apresentado já na primeira edição isolado em página inteira, anuncia que sua publicação se dá "por ocasião da descoberta do Brasil’ (Andrade, [1925] ${ }^{1}$ 2003, p. 97). Obviamente, elementos próprios de um Brasil anterior à "descoberta" oswaldiana serão costurados na trama desse longo e heterogêneo poema, inspirador de uma invejável fortuna crítica. No entanto, esse gesto inicial, que nega dimensões a serem, de

* Agradeço à Fapesp o financiamento da pesquisa de que este texto se origina.

Artigo recebido em 30/01/2014

Aprovado em 08/04/2014 fato, abordadas no desenrolar do poema, anuncia uma postura de negação, ou supressão, de parte da herança cultural brasileira que atravessaria o poema por completo.

Meu intuito é trazer à tona dessa trama poética uma dessas dimensões negadas no mote inicial mas retomadas repetidas vezes no corpo do poema: a figura do bandeirante, tão cara aos setores mais conservadores do período e surpreendentemente capaz de fazer emparelharem-se esses últimos e Pau Brasil, uma das expressões mais vanguardistas do modernismo paulista, embora ambos coloquem a questão de formas bastante diversas. Com isso será possível inserir o poema no debate de época, posicionando-o em um patamar de equivalência, embora não de semelhança ou de homogeneidade, com textos de naturezas diversas (sociológicos e historiográficos) para fazer saltarem os diferentes usos que as diversas perspectivas fizeram desse mito ressurgido no início do século XX. No confronto 
com a historiografia que evoca o bandeirante no período e com o contexto que ela pretende explicar, será possível perceber que, na pena oswaldiana, a retomada do bandeirante envolve a rasura da dimensão heterônoma implicada na recentemente extinta condição de colônia, a ser, evidentemente, obliterada - o que, aliás, exigia que todo o país, pela via da literatura, fosse descoberto com a publicação de Pau Brasil - e, com ela, da participação portuguesa em nossa herança cultural.

Para tal, proponho que se adote como perspectiva metodológica a desmontagem da hierarquia entre textos de naturezas diversas na consideração da possibilidade de que a literatura possa produzir conhecimento e mesmo se inserir em um debate, por assim dizer, multidisciplinar, sem descuidar, no entanto, da especificidade da linguagem literária. Esse passo envolve assumir o texto não só como produto social, cuja compreensão se dá na sua necessária remissão ao seu contexto, o que muitas vezes implica nele dar legibilidade apenas ao que pelo contexto se explica, mas também de entendê-lo como um intérprete de seu contexto (Gaudez, 1997, p. 31; Leenhardt, 1998, p. 105), como dimensão que tem algo a dizer sobre o cenário de sua produção a partir de especificidades de sua linguagem.

Não se trata, pois, de perscrutar as formas pelas quais o contexto paulista dos anos de 1920, que não será desconsiderado na análise, condiciona a leitura de Pau Brasil, seja dando relevo às condições materiais que as poderiam determinar, seja ressaltando as origens sociais e os interesses de seus atores, buscando simplesmente interpretá-lo à luz de dimensóes que o condicionariam. Diversamente, a postura metodológica aqui assumida envolve considerar o texto literário como uma dimensão social dotada de especificidades que o diferenciam desse contexto, embora com ele esteja em permanente diálogo, uma dimensão portadora de um papel mais ativo na interpretação sociológica, capaz de oferecer, ele próprio, uma leitura significativa de seu contexto de produção, o qual será aqui apresentado em duas dimensões: um contexto intelectual, em que se apreendem as diversas interpretaçôes que nos anos de 1920 se fazem da figura do bandeirante, e o contexto social da capital paulista a que essa retomada busca fornecer legibilidade e explicação histórica.
O mote inicial do livro como que sugere tal embocadura metodológica: possuindo a literatura o condão de "descobrir" o Brasil, ela aparece como portadora de atributos que, em alguma medida, a autonomizam em relação ao seu contexto, possuidora que é da capacidade de transformá-lo, reinventá-lo, dele suprimir parte de sua história.

Como se sabe, Pau Brasil é composto por blocos de poemas, no geral curtos, que atualizam em uma linguagem muito moderna acontecimentos da história brasileira. Nessa viagem exploratória, o poema apresenta um Brasil fragmentário, truncado e cheio de ambiguidades, um Brasil que em verdade se descobre à medida que o leitor é transportado em uma viagem cujo encerramento, de forma muito significativa, se dá em um cruzeiro que conduz o eu-lírico de volta a São Paulo, como se esse fosse o lugar último visado pela descoberta modernista da grande nação.

É nessa viagem, e compondo um projeto de descoberta literária do país, que a saga bandeirante será tematizada. A primeira menção à figura lendária se dá no poema que traz no título o nome do grande sertanista apresentado no bloco "História do Brasil":

FERNÃO DIAS PAES

carta

Partirei

Com quarenta homens brancos afóra eu

E meu filho

E quatro tropas de mossos meus

Gente escoteyra com polvora e chumbo

Vossa Senhoria

Deve considerar que este descobrimento

É o de maior consideração

Em rasam de muyto rendimento

E tambem esmeraldas

[Andrade, (1925) 2003, p. 117.]

Oswald de Andrade escolhe para essa empreitada uma das maiores figuras do bandeirismo paulista e, não por acaso, aquele entre os principais bandeirantes cuja família primeiro havia chegado à capitania de São Vicente e, portanto, 
pertencente já à segunda geração a nascer no que viria a ser São Paulo. ${ }^{2}$

O título do poema faz menção à carta de 21 de julho de 1674, enviada por Fernão Dias ao então secretário do Estado e Guerra, Bernardo Vieira Ravasco, irmão de Padre Vieira. ${ }^{3}$ Com esse artifício poético, Oswald dá voz ao próprio Fernão Dias, que figura como o eu-lírico desse trecho, em um traço tipicamente oswaldiano, presente também em Memórias sentimentais de João Miramar, Serafim Ponte Grande e outros textos, que é esse de compor o texto a partir de uma multiplicidade de autorias. Assim como a bandeira, também o poema é liderado pelo sertanista, que então apresenta a conformação da expedição que conduzirá até a almejada descoberta de esmeraldas na região das Minas Gerais, ressaltando, é claro, o grande potencial econômico que uma tal descoberta acarretaria para a Coroa portuguesa, o que, certamente, fala mais sobre a Coroa do que sobre o sertanista.

Aqui não há confronto com o jesuíta nem matança de índio. Bem ao contrário, esse poema apresenta os preparativos da expedição em uma entonação harmônica e pouco heroica. Essa perspectiva acentua-se quando se considera que, no conjunto do livro, esse poema se segue a outro, menor em tamanho mas adensador de significados, em que se mostra a atmosfera de concórdia com que o vilarejo vicentino convivia então com as vilas jesuíticas que o cercavam, povoadas por índios amistosos e padres capazes de doutriná-los:

prosperidade de São Paulo

Ao redor desta villa

Estão quatro aldeias de gentio amigo

Que os padres da Companhia doutrinam

Fóra outro muito

Que cada dia desce do sertão.

[Andrade, (1925) 2003, p. 116.]

Não só o termo "prosperidade" no título do poema mas também a figura de Fernão Dias serão retomados em um poema do bloco "São Martinho", onde o sertanista já figura como uma imagem recuperada do passado, capaz de cristalizar determinada atmosfera de época, rearticulada em um momento posterior a partir de uma série de associações que estão no seio mesmo da figura do bandeirante retomada no século XX:

prosperidade

O café é o ouro silencioso

De que a geada orvalhada

Arma torrefaçōes ao sol

Passarinhos assoviam de calor

Eis-nos chegados à grande terra

Dos cruzados agrícolas

Que no tempo de Fernão Dias

E da escravidão

Plantaram fazendas como sementes

E fizeram filhos nas senhoras e nas escravas

Eis-nos diante dos campos atávicos

Cheios de galos e de reses

Com porteiras e trilhos

Usinas e igrejas

Caçadas e frigoríficos

Eleiçôes tribunais e colônias

[Andrade, (1925) 2003, p. 131.]

Já no primeiro verso o poema explicita a que universo se refere com o título: trata-se da pujança econômica promovida pelo cultivo do café em terras que são de imediato associadas às conquistas das bandeiras, aqui representadas pela figura do célebre sertanista. A associação é reafirmada pela aproximação entre o ouro, visado pelas expediçōes do século $\mathrm{XVIII}$, entre as quais figuram como as mais célebres aquelas lideradas por Fernão Dias, e o café, que no século XIX viria preencher os campos paulistas e daria a essa terra a prosperidade a que se refere o título. A expressão "cruzados agrícolas" condensa a histórica associação, presente na historiografia da segunda metade do XIX e das primeiras décadas do XX responsável pela retomada do símbolo bandeirante, entre a conquista territorial das expedições bandeirantes e o cultivo do café que daria a São Paulo a dianteira econômica do país, então cultivado no que o poema anuncia como "plantio de fazendas", tal como se fossem sementes.

Essa São Paulo próspera aparece como resultado de um processo histórico cuja linha de continuidade permite a convivência de caçadas, mais primitivas, 
e frigoríficos, mais modernos, de usinas e igrejas, fazendas com porteiras e trilhos. Os elementos que caracterizam a prosperidade do moderno não apenas convivem com remanescentes do passado, mas resultam de elementos desse mesmo passado, em que figura com centralidade o grande sertanista descobridor de ouro.

Sua exaltação será retomada no poema que recebe o nome da cidade mineira de Sabará, que integra o bloco "Roteiro das Minas":

sabará

Este córrego há trezentos anos

Que atrai os faiscadores

Debaixo das serras

No fundo da bateia lavada

O sol brilha como ouro

Outrora havia negros a cada metro de margem

Para virar o rio metálico

Que ia no dorso dos burros

E das caravelas

Borba Gato

Os paulistas traídos

Sacrilégios

$\mathrm{O}$ vento

[Andrade, (1925) 2003, p. 187.]

O poema é dedicado à temática da exploração de minérios em seu período áureo. Apresentada como polo de atração daqueles que confiavam em ali fazer riqueza, o riacho de Sabará conta uma história de exploração, não do ouro, que aparece aqui como elemento de sedução, mas da pretensa riqueza nacional, que no dorso dos burros e à bordo das caravelas alcança a Europa. A miragem do ouro, que não passa de imagem do sol refletida no fundo da bateia, alude a essa dimensão volátil do que foi a esperança de se fazer riqueza em território americano, usurpado pelo colonizador português.

O que vem redobrar o aspecto idílico da atividade mineradora nas linhas desse poema é, naturalmente, a referência a outro bandeirante, Manoel de Borba Gato (Leme, 1904, p. 454), genro de Fernão Dias Paes Leme. A Guerra dos Emboabas é claramente referida pelo verso "os paulistas traídos", em que se apresentam não só o conflito entre paulistas e reinóis pela exploração das minas, mas também uma tomada inequívoca de partido dos paulistas quando o eu-lírico considera traídos os paulistas que reivindicavam o monopólio da exploração por haverem primeiro alcançado as minas auríferas. $\mathrm{O}$ sertanista paulista aqui, se não é exatamente um herói, é uma espécie de detentor de privilégios de exploração advindos de sua habilidade exploradora.

Como se sabe, é por parte do governo português e de exploradores oriundos de diferentes regiōes do Brasil que nasce a investida contrária que culmina com a derrota dos paulistas (Abud, 1985, pp. 35-36; Souza, 2000, p. 269). O lamento da derrota paulista e a perda dos seus direitos exclusivos de exploração são tratados no poema por sacrilégio, em um claro endosso da precedência do direito dos paulistas sobre a exploração das minas e na outorga da pecha de vilania aos reinóis oportunistas.

A retomada da figura do bandeirante na poesia oswaldiana certamente não possui aquela tonalidade ufanista que pairava na atmosfera paulista no período de sua escrita. A complexidade das proposições que essa poética modernista constrói excede em muito a simples tessitura de um herói inconteste a ser enaltecido nos termos que ela mesma tão veementemente criticava nos literatos que a precederam, notadamente nos parnasianos. No entanto, o nacionalismo que atravessava diferentes esferas da vida cultural brasileira naquele momento - dos movimentos literários às artes plásticas, da historiografia aos projetos políticos -, a valorização da nação e a apresentação de projetos para a sua modernização, que surgem especialmente no cenário paulista, fazem-se presentes também em Pau Brasil, por vezes com a utilização dos mesmos símbolos.

Como já anunciado, é importante mencionar que nos anos de 1920 a historiografia trazia novamente para o centro da cena paulista a figura do bandeirante. Nesse cenário, o bandeirante redescoberto, a despeito da heterogeneidade que deriva da multiplicidade de perspectivas que a ele recorrem, se estabelece como uma espécie de eixo interpretativo da história colonial paulista. Abud (1985), Queirós (1992), Glezer (1992), Monteiro (1994), Adduci (2000) e Ferreti (2008) estão de acordo sobre o lugar de origem dessa tradição: ela data do 
século XVIII e saiu da pena de Pedro Taques de Almeida Paes Leme, que desenha a fisionomia do paulista como um herói militar na produção dos textos História da capitania de São Vicente, Notícias das minas de São Paulo e dos sertões da mesma capitania e sua grandiloquente Nobiliarquia paulista histórica e genealógica, e de Frei Gaspar da Madre de Deus, que valorizaria a origem mameluca e a determinação geográfica do tipo paulista na escrita de suas Memórias para a história da capitania de São Vicente. A imagem plasmada pelos trabalhos de Pedro Taques e Frei Gaspar aparece, assim, reeditada em um contexto que é capaz de produzir dividendos políticos, o início do século XX, momento em que se recupera do século XVIII uma interpretação linhagista dos sertanistas paulistas, emaranhada na chamada "lenda áurea" que trará à vida uma mística imbuída de heroísmo e altivez, por meio da qual se vê no bandeirante a figura cujo esforço empurra para oeste os limites de influência da Coroa portuguesa em território americano.

Essa lenda é uma resposta ao que se sedimentou no século anterior por meio, sobretudo, dos registros dos jesuítas espanhóis, notadamente de Antonio Ruiz de Montoya, Francisco Jarque e, posteriormente, os jesuítas franceses Pierre François Xavier Charlevoix e Vaisette (Abud, 1985, p. 3), cujas reduçōes foram assaltadas e dizimadas pelos sertanistas paulistas, registros que consolidaram o que se chamou de lenda negra (Glezer, 1992; Monteiro, 1994; Souza, 2000).

Sua retomada ao final do século XIX é utilizada em contexto político muito específico: no auge do descontentamento dos paulistas, notadamente dos integrantes do Partido Republicano Paulista, ressentidos da desproporção entre a contribuição econômica que São Paulo dava ao país e a diminuta participação política que tinham em um governo demasiado centralizado, a propaganda federativa alcançaria pretensões separatistas, que advinham precisamente de figuras da elite paulista localizada no seio do partido. Seus porta-vozes utilizavam como propaganda precisamente a figura do bandeirante, imagem que condensava as conquistas dos paulistas, seu brio e sua personalidade destemida, uma gente que desde sempre se mostrou independente, autônoma, destinada a ser não só a locomotiva eco- nômica, mas também a locomotiva civilizacional do Império, aquela cuja força motriz, para usar os termos de Martim Francisco, arrastaria atrás de si 22 vagões.

Segundo Adduci (2000), todos os seus adeptos, em algum momento, farão uma discussão sobre a nação, fazendo-a coincidir, de formas diferenciadas, com uma certa ideia de paulistanidade. À exceção de Martim Francisco, todos eles recorreram a uma dimensão de tradição histórica para justificar uma nacionalidade paulista, junto da qual mobilizaram argumentos ligados ao caráter da população local, sua origem, sua etnia, seus limites geográficos, sua coincidência de interesses.

Por detrás desse projeto político ressurge o mito bandeirante como figura capaz de exprimir todos esses aspectos, sendo construído como sinônimo de "iniciativa, coragem, audácia, vigor, capacidade de conquista e elemento civilizatório" (Adduci, 2000, p. 143), o que explicaria e justificaria a superioridade paulista no conjunto das províncias que constituíam o Império, muitas delas consideradas pelos adeptos de tais teorias como "filhas de São Paulo", caso de Minas Gerais e Paraná, territórios cuja ocupação se deve à ação bandeirante.

Certa mentalidade da supremacia e superioridade paulistas não se dissiparia com a frustração do projeto separatista, enfraquecido com o advento da república, que ressurgiria no início dos anos de 1930. Antes disso, no entanto, a figura do bandeirante volta ao debate, então como elemento que ajudaria a explicar o desenvolvimento econômico que São Paulo presencia na entrada do século XX.

Será nas linhas da História geral das bandeiras paulistas, principal obra historiográfica de Affonso d'Escragnolle Taunay, constituída de onze volumes publicados entre 1924 e 1950, que se consolidará a imagem do bandeirante como responsável direto pelo maior movimento expansionista da história brasileira. Em perfeita consonância com seus trabalhos como editor da Nobiliarquia paulista, de Pedro Taques, e diretor do Museu Paulista, cuja reordenação e "divisão em dois setores bem distintos - um, dedicado à história brasileira e o outro totalmente dedicado à história de São Paulo - foi apenas uma metáfora que visava inocular a ideia de que São Paulo foi o 'berço da nacionalidade" 
(Saliba, 2004, p. 570), essa perspectiva inevitavelmente atravessaria as milhares de páginas de sua história bandeirante.

Vale lembrar as estátuas dos dois maiores ícones do bandeirismo paulista que ocupam o saguão de entrada do Museu Paulista, em uma disposição orquestrada por Affonso Taunay como diretor do $\mathrm{Mu}$ seu quando das comemoraçóes do Centenário da Independência, ${ }^{4}$ disposição que, por sua orientação, deveria dar destaque a

[...] todos os grandes lances da História do Brasil revestindo o edifício do Museu de uma feição de pantheon, empolgadora ao primeiro contato da vista dos visitantes com as suas pinturas e esculturas. [...] No Saguão, a fim de ocupar quatro painéis e oito locais para retratos, a concepção original homenageou as "primeiras manifestações de independência do espírito nacional" - cena da Inconfidência Mineira, Guerra dos Emboabas, Guerra dos Mascates e Rebelião Mineira de 1720. [...] No Saguão ficaram duas esculturas em mármore medindo cada uma delas três metros de altura incluindo o pedestal, feitas por Luigi Brizzolara, estatuário italiano de renome. As duas estátuas, no dizer de Taunay, resumiriam as fases do bandeirantismo: Antônio Raposo Tavares, o ciclo da busca da mão de obra indígena, seja no sertão, seja nos aldeamentos jesuíticos; e a devassa e exploração do distante sertão. [...] Fernão Dias Paes Leme simboliza a fase seguinte, aquela do descobrimento do ouro e de pedras preciosas, inaugurando-se o chamado "ciclo do ouro", com o povoamento do sertão (Makino, 2002-2003, p. 172).

Se esse autor, como afirma Katia Abud, seguiu a pista indicada por Capistrano de Abreu, para quem a historiografia brasileira, até aquele momento, havia se dedicado demasiado ao litoral, deixando por construir uma história do interior do território brasileiro, assim como julgava necessário que se fizesse estudo mais minucioso sobre o seiscentismo paulista, Taunay se distancia daquele na valoração da figura do bandeirante, já que foi o mesmo Capistrano de Abreu um dos primeiros historiadores a denunciar a matança de índios por parte dos sertanistas paulistas. Sua apreciação da atividade bandeirante, eivada de preconceito racial, reconhece, no entanto, que é do mameluco, tipo ambientado ao seu contexto, que deveria vir o homem capaz de enfrentar os sertôes, porque esse era produto de uma miscigenação superior, na qual o elemento indígena seria, com o tempo, diluído em um processo permanente de arianização.

A dizimação daqueles que o autor considera povos inferiores, como os índios, não desonera a grande atividade bandeirante que deu ao Brasil seu contorno territorial mais amplo, e considera mesmo que o que se convencionou tomar como barbarismo dos sertanistas paulistas era, de fato, um dado de época, que não lhes conferia nenhuma particularidade. $\mathrm{O}$ núcleo na análise feita por Taunay se localiza na expansão territorial, a despeito da despovoação indígena que promovia.

Por sua vez, Alfredo Ellis Jr. - autor de Alguns paulistas dos séculos XVI e XVII: subsidios para a história de São Paulo, de 1922; Novas bandeiras e novos bandeirantes, também de 1922; O bandeirismo paulista e o recuo do meridiano: pesquisas nos documentos seiscentistas, de 1924; e sua obra fundamental, publicada em 1926, Raça de gigantes, que em segunda edição recebe o nome de $O s$ primeiros troncos paulistas - está interessado em sedimentar uma concepção de raça paulista. Buscando dar estatura científica ao seu estudo, Ellis Jr. utiliza recursos conceituais do evolucionismo e do determinismo geográfico, buscando "provar que o cruzamento entre o branco ibérico e o ameríndio, no planalto de São Paulo, teria gerado uma sub-raça superior, que deu origem 'às bases causadoras da formidável superioridade do paulista' (Ellis Jr., 1936, p.19)" (apud Abud, 1985, p. 144). O bandeirante emerge dessa análise como prova de tal superioridade, que marcaria ininterruptamente dos portugueses e dos mestiços expedicionários do século XVII aos cafeicultores do XIX. Bandeirante e paulista, nessa acepção, são tomados como sinônimos.

Em uma tônica bastante diversa, Paulo Prado publica Paulistica em 1925. A meu ver, a imensa sedução que lhe causa a figura mítica do ancestral bandeirante não permite, tal como defende Abud, que a análise dessa personagem seja con- 
siderada nos mesmos termos que as de Taunay e Ellis Jr. Prado aceita uma sugestão de Capistrano de Abreu, para quem a história colonial de São Paulo possuía certo desenho que envolve ascensão (expansão colonizadora do século XVII pelas bandeiras de apresamento), clímax (conquista das minas no século XVIII pelas bandeiras auríferas e triunfo na luta contra os espanhóis), decadência (despovoamento e perda dos territórios de Minas Gerais, Goiás e do sul na passagem do XVIII para o XIX, resultado da retomada da máquina política pelos governadores portugueses e da derrota na Guerra dos Emboabas) e regeneração (expansão econômica do café nos séculos XIX e XX), dentro da célebre curva senoide esquematizada já na abertura do livro.

A perspectiva histórica que aqui se exprime, diversamente do que se vê em Ellis Jr. e mesmo em Martim Francisco, um dos idealizadores intelectuais do movimento separatista de 1887 , permite ao menos que se vislumbre um período de decadência em meio ao que só se lê como triunfo na historiografia desenhada pelos outros dois. Por outro lado, a decadência se dá precisamente na descentralização política da gente paulista, deslocada pela ascensão dos governadores portugueses, expressão acabada do "parasitismo do estado peninsular" (Berriel, 2000, p. 134).

Também não encontramos aqui sinal da valorização da arianização presente tanto em Ellis quanto em Taunay. Bem ao contrário, a pura raça paulista resulta da mescla do índio com o português, aqui reconhecido por sua doçura na contraposição ao devastador espanhol, antes mesmo que, como bem salienta Carlos Augusto Calil (2004, p. 12), o fizesse Gilberto Freyre. O paulista é, por definição, um mameluco:

[Fernão Dias] viveu nos tempos em que melhor se afirmaram os fortes caracteres desse tipo social que as circunstâncias criaram na capitania de São Vicente. Pertencia a antiga e poderosa família, cujos ascendentes desde 1550 residiam na colônia. Apesar das numerosas justificações de sangue limpo e da mania nobiliárquica da época, um longínquo cruzamento com indígena dava-lhe sem dúvida esse cunho mamaluco que é a nota aristocrática do paulista puro (Prado, [1925] 2004, pp.181-182).
Se não se encontra o elemento racista na análise de Prado, o orgulho da raça paulista ecoa inequivocamente de todas as suas páginas. O lustro epopeico produzido por Taques, autor citado incontáveis vezes no capítulo "Bandeiras", e por Frei Gaspar reluz aqui em uma linguagem moderna, limpa, do século. O bandeirante que por ela se delineia não é menos heroico, e a sedução que exerce sobre seu autor é incontornável.

Como resultado da concorrência de fatores das diversas ordens, o mito bandeirante é capaz de vertebrar todo um projeto nacional que tem São Paulo como centro. Se, na concepção de Prado, a história do Brasil orbita em torno da história de São Paulo, e essa, por sua vez, só se entende em razão do tipo humano que nessas terras se constituiu, cuja expressão mais emblemática é o próprio bandeirante, por essa perspectiva se compreende e se justifica a supremacia econômica de São Paulo no contexto nacional dos anos de 1920, entendendo-a como uma das expressões da história de conquistas dessa raça heroica, de toda forma superior, inclusive em seus atributos físicos:

Do cruzamento do forte sangue português quinhentista, dos franceses, castelhanos e flamengos com as cunhãs, o mamaluco surgiu perfeitamente aparelhado para o seu destino histórico. A montanha isoladora dos contágios decadentes do litoral; a atitude sempre sobressaltada de quem vivia na orla das imensas matas virgens, sombrias e espessas; a convivência diária e íntima com o gentio da terra de quem falava corretamente a língua; a feliz situação geográfica e topográfica, que o locava à margem e nas proximidades de grandes rios, descendo para o interior das terras; a aspereza fortificante de um clima de bruscas variações, em que às geadas das manhãs claríssimas sucedem sóis abrasadores do meio-dia - todos esses fatores conjugados criaram um admirável exemplar humano, belo como um animal castiço, e que só puderam realizar nessa perfeição física os homens da Renascença italiana, quando César Bórgia seduzia o gênio de Maquiavel (Idem, p. 147). 
Ao lado da mística paulista que transparece neste longo mas necessário trecho reproduzido de Paulística, sobressaem os elementos que darão substância à precisa definição de paulista empreendida por Paulo Prado, que se delineia dentro de um esquema geral de definição das raças, tal como explicita Berriel: "no processo de formação das raças atuam três fatores: primeiro, a adaptação dos indivíduos imigrados às novas condiçóes de vida que encontram; segundo, a transmissão dos característicos individuais dos primeiros colonos aos seus descendentes, efetivada pela reprodução entre consanguíneos; terceiro, a ação niveladora e compensadora do cruzamento" (Berriel, 2000, pp. 134-135), que, no caso da gestação da raça paulista, contou com o papel decisivo da Serra do Mar, quase intransponível, na circunstância de isolamento que permitiria a esse "experimento" humano se desenvolver quase sem interferência posterior do colonizador.

Se a perspectiva de Paulo Prado se distancia da tônica de Ellis Jr. e de Taunay no que se refere à valorização da miscigenação como elemento positivo na constituição da raça paulista, ela se aproxima no que se refere ao legado fundamental deixado pelo bandeirante na história colonial brasileira: o ganho territorial posto em evidência em análises díspares em múltiplos aspectos, mas que igualmente consideram o empreendimento bandeirante não apenas em uma perspectiva psicogenética do seu tipo humano, mas, fundamentalmente, em uma lógica geopolítica:

A essas qualidades guerreiras, que a metrópole soube tão bem aproveitar, juntavam os paulistas um forte incentivo que era o velho ódio ao espanhol. Assim essas expedições de morte e extermínio - de despovoamento, como diz Capistrano - vieram pelas suas conquistas corrigir a linha divisória de Tordesilhas, e fazer recuar o avanço castelhano que se insinuava pelos grandes rios do sertão meridional (Prado, [1925] 2004, p. 141).

É precisamente para desmontar essa perspectiva que John Manuel Monteiro, quando toda a historiografia bandeirante passa por uma revisão de fundo, apresenta, em Negros da terra, uma leitura que se encaminha em sentido inteiramente diver- so. Com base em ampla documentação, Monteiro coloca em outro patamar a provocadora indagação de Capistrano de Abreu, que tanto incômodo provocou em Paulo Prado:5 "compensará tais horrores a consideração de que por favor dos bandeirantes pertencem agora ao Brasil as terras devastadas?" (Abreu apud Prado, [1925] 2004, p. 133). Em confronto direto com a historiografia do século XVIII, heterogeneamente reeditada nos anos de 1920 e 1930, John Monteiro dará visibilidade ao aspecto periférico do impacto geopolítico da atuação dos sertanistas, permitindo que se perceba a centralidade da dimensão de escravização envolvida nessas expedições de apresamento de índios para abastecimento das atividades econômicas agrícolas na capitania, salientando que

[...] a maior parte das grandes expedições tinha como objetivo as numerosas aldeias guarani no Guairá. [...] Tanto os povoadores do Paraguai quanto os portugueses de São Paulo disputavam o acesso à mão de obra existente neste vasto e vagamente definido território que separava os extremos dos respectivos impérios ibéricos. Entretanto, nenhum dos dois mostrava-se interessado na ocupação efetiva do lugar, desejando antes apenas fazer cativos guarani, ao mesmo tempo que procuravam evitar contatos mais intensos com outros grupos indígenas que viviam nas regiōes limítrofes, conhecidos por sua belicosidade (Monteiro, 1994, pp. 68-69).

Por sua vez, Antônio de Alcântara Machado oferece à lendária figura do bandeirante uma perspectiva inteiramente diversa. Dando o primeiro passo para o que Sergio Milliet chamaria de "a importância da influência cultural na formação e no desenvolvimento do bandeirismo" (Milliet, 2006, p. 17), com a publicação de Vida e morte do bandeirante Alcântara Machado descerá ao chão da dura vida de todos os dias enfrentada por esses homens no sertão meridional no que foi sua única obra historiográfica. Para muito além de inventariar as vestimentas, o mobiliário, os utensílios domésticos, de caça, rituais de morte e de luto, o autor mobiliza esses elementos na constituição de verdadeiros estilos de vida, dando densidade a uma atmosfera cultural que, se não é no- 
bre e aristocrática, é igualmente heroica em vista da imensa assimetria posta entre a singeleza dos recursos de que dispunham os vicentinos e o vulto das conquistas a que chegaram.

Se o autor, como quer Milliet, "tira dos documentos um bandeirante pobre e analfabeto, grosseiro, de modos e haveres parcos, vivendo quase na indigência, duro para consigo mesmo e com os semelhantes, austero e primário, em luta permanente contra dificuldades de toda espécie, amante apavorado do sertão, e por todas essas razões naturais sensatas, lógicas, capaz de arrancadas maravilhosas que não se lhe apresentavam como oportunidades de glória mas sim como soluçôes de inexorável urgência" (Idem, p. 17), a contribuição dada por essa perspectiva à chamada mística paulista muda de fisionomia mas não se dissipa. Antes, a não intencionalidade do gesto de bravura, destituído de pretensões de glória e produzido pelo desafio diário à sobrevivência, confere a esse herói um acréscimo de modéstia e mesmo de ingenuidade que só faz engrandecê-lo.

Isso é demonstrado no trecho final do livro, em que Machado descreve a cena de partilha dos despojos do sertanista Pascoal Neto:

O produto das peças e os bens que não acham licitante, recebe-os o curador que para tal mister foi elegido. Assim também, os negros vindos em companhia do defunto e os novos que lhe foram dados em partilha, para ilhá-los e dando Deus remédio levar para povoado.

Responsabilidade formidável naquele ambiente carregado de incertezas. Por isso mesmo, o curador protesta que tudo corra por conta e risco da viúva que foi do defunto, e herdeiros seus... para que em nenhum tempo, sucedendo alguma cousa... lhe peçam conta. O capitão limita-se a ordenar que se tome o protesto, dizendo desabria mão, remetendo tudo à justiça de Sua Majestade. Os sufrágios religiosos e as custas são pagos em fazenda. Terá o capelão uma arroba de cera pela missa. Terá o escrivão um machado, umas armas velhas, ou coisa de cinco arráteis de cera. Dos capitães só um reclama a paga de seu trabalho: Antonio Raposo
Tavares. Da pobreza que fica por morte de Pascoal Neto, o heroico devastador das missões retira um par de meias (Machado, [1929] 2006, pp. 262-264).

Trinta anos mais tarde esse mito ainda reverberaria na historiografia de primeira ordem. Jaime Cortesão, em conferência intitulada "A maior bandeira do maior bandeirante", proferida na Faculdade de Filosofia, Ciências e Letras da Universidade de São Paulo, e posteriormente publicada na Revista de História por ocasião de sua morte, apresenta uma leitura das bandeiras centrada na dimensão política de consolidação e ampliação da ocupação portuguesa em território americano, iniciando com as expedições de Fernão Dias e chegando às extraordinárias façanhas de Antonio Raposo Tavares. Ele argumenta que os empreendimentos dos bandeirantes são decorrência inequívoca da necessidade política de ampliação do território português até pelo menos o Rio da Prata, dimensão que, portanto, deve orientar a interpretação histórica de sua atuação.

Em inexcedível reconhecimento da grandeza desses bandeirantes, e lançando mão de uma das mais assentadas figuras épicas de seu país, é a nada menos do que aos Lusíadas que Cortesão compara o sertanista paulista:

Para enaltecer seu esforço e bravura, alguns historiadores brasileiros chamam a Raposo Tavares - homeríada. Seja-nos lícito fazer um reparo. Dos heróis de Homero decorreram os horrores no Mediterrâneo, mar interior cuja maior extensão não ultrapassa quatro mil e quinhentos quilômetros; e cujos perigos não excediam o canto das sereias e o agitado mar entre Cila e Caríbedes, no doméstico estreito de Messina. Se temos de comparar aqueles bandeirantes a grandes navegantes há que recorrer então aos descobridores, que afrontam os cabos das Tormentas, que dividem os Oceanos. Como Vasco da Gama no Indico, ou Fernão de Magalhães no Pacífico, Raposo Tavares mediu a sua grandeza pelos dois maiores padrões da Natureza no seu gênero: os Andes e o Amazonas. Por mais a despropó- 
sito que se tenha usado e abusado da palavra, acreditamos que a Raposo Tavares e aos seus companheiros cabe, sim, por justo título e direito, o qualificativo mais épico, mais nobre, mais humano e mais brasileiro de Lusíadas (Cortesão, 1961, p. 27).

A despeito da multiplicidade de perspectivas que surgem nos anos de 1920 e 1930, a figura do bandeirante é recuperada de forma a estruturar a história colonial brasileira em uma tônica quase inspiradora de projetos que se outorgam nada menos do que reconstruir ou "redescobrir" a nação.

Ora, é correlato deste contexto intelectual, em que o mito bandeirante é reinvestido da força de explicação histórica dos séculos de dominação colonial, um contexto sociopolítico em que os ares modernizadores, ressaltados por Carone (1969), Morse (1970), Love (1982), Sevcenko (1992 e 1998), Saes (2004), inspiravam um léxico de autoafirmação respaldados sobretudo na dianteira econômica com que São Paulo despontava na cena nacional do período. Mas o mito bandeirante não se presta, como instrumento político, apenas à afirmação da primazia paulista em face da nação, mas apresenta uma segregação interna ao contexto paulista, operando ali como sintagma da superioridade de um grupo específico.

São Paulo vivia naquele momento uma fervilhante transformação com o desembarque de diversos elementos que lhe chegavam de fora. Interessa-me particularmente aqui a análise feita por Flávio Saes (2004) acerca do desenvolvimento econômico de São Paulo e os elementos que se engatam nesse processo: o capital cafeeiro, o capital externo e o empresário migrante.

A transferência da atividade cafeeira do vale do Paraíba para o Oeste paulista e a substituição da mão de obra escrava pelo trabalho imigrante livre e assalariado confere a essa atividade uma racionalidade capitalista ainda inédita no cenário produtivo brasileiro. Parte considerável da oligarquia cafeeira é aquela que investirá nas atividades industriais paulistas (Costa, 2010, p. 262) e financiará as transformações na fisionomia da cidade, que será considerada, portanto, a "capital do capital cafeeiro"6 (Saes, 2004 , p. 240). Ora, também a oligarquia cafeeira, como aponta Martins (2004), pode ser considerada uma imigrante na sua capital, tendo em vista que é das fazendas de café do interior paulista que parte substantiva desse grupo se mudará na busca da consolidação de estilos de vida mais cosmopolitas. Também ela é um elemento adventício na capital em transformação.

O capital estrangeiro está presente de diversas formas, mas certamente as companhias mais emblemáticas são a São Paulo Light and Power Company, empresa de capital canadense instalada em São Paulo em 1899, e a City of São Paulo Improvements and Freehold Land Co., que desembarca trazendo consigo ares europeizantes em um urbanismo importado que desmata o que resta da Mata Atlântica no cimo da mais alta colina da cidade:

Enquanto o inglês Barry Parker metamorfoseava o Parque da Avenida, os franceses Bouvard e Couchet redesenhavam a orla da colina central da cidade, apagando os últimos traços originais ao redor do santuário onde os jesuítas haviam celebrado a sua fundação, transformando as vertentes do Anhangabaú e os pântanos do Tietê num panorama cenográfico dos mais elegantes, com toques finos de décor europeu ponteados de palmeiras e vastos tapetes gramados, recortados de trilhas, passeios e canteiros (Sevcenko, 1992, p. 115).

O terceiro elemento estrangeiro salientado por Saes é composto de um grupo de empresários estrangeiros entusiasmados com as possibilidades de investimento na capital paulista, grupo em que Francisco Matarazzo é acompanhado por Alexandre Siciliano, Rodolfo Crespi, Egídio Gamba, Giuseppe Puglisi Carbone, Nami Jafet, entre outros.

Não se pode deixar de considerar a presença maciça da mão de obra imigrante que não se dirigia integralmente às fazendas de café, ou que a partir dela retornam aos centros urbanos, notadamente para São Paulo: "só o Estado de São Paulo recebeu, em pouco mais de um decênio, isto é, entre 1890 e 1901, cerca de setecentos mil colonos: italianos, portugueses, espanhóis e austríacos, não contando os de outras nacionalidades" (Costa, 2010, p. 254). A cidade vai assim ganhando uma multiplicidade 
de elementos adventícios que nela se encontram, de forma por vezes mais conflituosa, por vezes menos.

É com esse cruzamento dos elementos estrangeiros que estão em diálogo a historiografia de enaltecimento do mito bandeirante e os diferentes projetos literários, entre os quais figura Pau Brasil. Assim, se é preciso ter em conta o que apontam Katia Abud (1985), Maria Helena Capelato (1985), Maria Isaura (1992), Marly Motta (1992) e Danilo Ferretti (2008) quanto à utilização política da figura do sertanista em seu ressurgimento nos anos de 1920 e 1930, à luz dessa perspectiva que dá destaque à grande presença do elemento externo no vórtice transformador que vai se desenhando na capital paulista desde o final do XIX, é possível ainda sugerir uma outra utilização desse mesmo símbolo: em um contexto em que os componentes das novas forças transformadoras são externos à cena paulistana, há que se forjar um elemento que garanta algum enraizamento. Um grupo social em especial, sistematicamente representado na historiografia que enaltece o bandeirante, tem de onde recuperá-lo, e ao fazê-lo consolida o fator que justifica uma clivagem social interna.

Atestando a antiguidade de um determinado tipo social nesse território, dele propondo interpretações que percorrem caminhos diversos, mas chegam quase sempre à afirmação de um tipo racial, único e específico do meio, heroico, altivo e, em verdade, aquele a quem se devem as conquistas não só paulistas, mas também nacionais, não se dispõe apenas de um argumento em favor da supremacia do paulista no contexto político nacional, o que já está bastante bem assentado pelos intérpretes do período, mas também o forjamento de um símbolo que justifica o corte interno no contexto da capital paulista. Dotado de uma dimensão também política, mas com objetivos diversos, o recurso à ancestralidade no uso da terra, tomada à força como aponta Monteiro (1994), dá a esse grupo, também adventício na capital paulista, ${ }^{7}$ o elemento pelo qual se explica seu pertencimento à terra. Com isso ele se pode afirmar como seu único e legítimo herdeiro porque composto, desde há séculos, de seus verdadeiros conquistadores. Nenhum outro grupo teria direito à sua posse e exploração como esse que, nessa linha de argumen- tação, detém sobre ela direitos históricos. O mito aqui é recuperado para forjar um elá social onde havia um conjunto demasiado heterogêneo, e quase sempre adventício. Formulou-se um elemento simbólico que desse enraizamento a um determinado "povo", que assim adquire ares de nacionalidade, a nacionalidade paulista. No entanto, todas as vezes em que foi necessário afirmar uma clivagem interna que justificasse a superioridade de parte dessa população, o mesmo símbolo veio em socorro de tais interesses.

No esforço teórico de apresentar os recursos analíticos de uma sociologia estética, Bruno Péquignot toma da arte, como componente social, seu atributo de questionamento: "ela é atividade de questionamento, como a filosofia ou a ciência, mas em um registro completamente diverso, ela é atividade de questionamento pela implementação de um mundo cuja própria existência coloca em questão os mundos que vieram até ela" (Péquignot, 1993, p. 207). À luz dessa perspectiva teórica, e tendo delineado o contexto intelectual em que o mito bandeirante é reposto nos anos de 1920 e 1930 e o contexto sociopolítico da capital paulista no qual se faz útil, é possível retomar a pergunta inicial: qual é a leitura crítica apresentada por Pau Brasil ao reflorescimento da mitologia bandeirante e a que ela se presta no conjunto de suas proposições?

Claramente, a leitura fornecida por Pau Brasil não se emparelha com a perspectiva sobrecarregada de preconceito racial proposta por Ellis Jr., nem à narrativa monumentalizada de Taunay. Tampouco se mostra orgulhosa da raça, tal como se vê em Paulistica, ou ainda, romântica e idílica como em Alcântara Machado. Mais ainda se distancia do vezo autoritário incutido por Cassiano Ricardo em seu texto "O Estado Novo e seu sentido bandeirante", para quem a bandeira, que deveria servir de exemplo à configuração política do século XX, era um microcosmos de Estado em formato republicano, liderada por um chefe forte e luminar capaz de encaminhar as massas para seu destino de grandeza (Ricardo, 1941).

Não há em Pau Brasil vestígios da entonação epopeica da Nobiliarquia paulista de Pedro Taques, que, aliás, não poderia ser mais avessa ao 
estilo oswaldiano, considerado na ponta de lança das transformações estéticas da fase dita heroica do modernismo paulista (Fonseca, 2007; Campos, 2003 e 2004). Diversamente, é no estilo montado em ironia que Oswald apresentará uma perspectiva curiosa de uma versão contemporânea da expedição bandeirante:

ideal bandeirante

Tome este automóvel

E vá ver o Jardim New-Garden

Depois volte à Rua da Boa Vista

Compre o seu lote

Registre a escritura

Boa firme e valiosa

E more nesse bairro romântico

Equivalente ao célebre

Bois de Boulogne

Prestações mensais

Sem juros

[Andrade, (1925) 2003, p. 169.]

Intriga o leitor a forma como o sertanista preador de índios, devastador de reduções jesuíticas, cruel, rude e oportunista, descobridor de esmeraldas, conquistador de territórios, responsável pelo desenho geográfico do país-continente, e o bon vivant da capital paulista nos anos de 1920 são postos no mesmo patamar pelo título do poema, ao qual o leitor retorna após ler o último verso, curioso das implicações dessa associação.

Os cavalos e as embarcações seiscentistas cedem espaço ao automóvel; a mata fechada que desafia cotidianamente a sobrevivência é o painel de fundo substituído pela paisagem urbana do New-Garden; os obstáculos topográficos de difícil transposição desaparecem em um cenário que permite um constante e inconsequente ir e vir. O conquista da terra, resultado da sua tomada à força ao gentio bravio ou ao padre espanhol, não é sequer uma reminiscência onde se pode comprar em prestaçōes um lote de terra devidamente registrado em escritura pública. A aridez que comove o leitor de Alcântara Machado é velharia soterrada sob o recém-construído bairro romântico onde sopram brisas semelhantes aos do Bois de Boulogne.
Jorros de ironia dão outra dimensão a essa figura lendária que aqui não se captura nem pela lenda negra dos jesuítas espanhóis nem pela lenda áurea de Taques e Gaspar, que tanta tinta fez correr no início do século passado.

Isso não significa, no entanto, que esse conjunto poético que é Pau Brasil não apresente uma interpretação histórica do Brasil em que o mito bandeirante não emerja como um de seus vórtices explicativos, ressaltados em diferentes momentos de sua história e que seja, portanto, capaz de atravessá-la diacronicamente, aparecendo como dimensão que lhe confere alguma coerência histórica. Também nas páginas de Pau Brasil paira, menos potente, certamente menos coerente, dotado de fissuras e conflitos próprios ao estilo modernista de Oswald, a velha imagem de Fernão Dias Paes Leme, que não chega a ser exatamente uma imagem confrontadora daquela que o considerava, no mesmo momento, o maior de todos os sertanistas. O bandeirante também é fundamental para essa narrativa de descoberta do Brasil, apresentando-se em convivência harmônica com o gentio amigo e com o padre doutrinador que figuram em "prosperidade de São Paulo"; como ator injustiçado pelos reinóis na Guerra dos Emboabas que se lê em "sabará"; e ainda como empreendedor da cruzada agrícola em direção ao interior do continente a quem se deve o desenvolvimento econômico de São Paulo nos anos de 1920 que se presencia em "prosperidade".

Nesse sentido, o poema se insere no conjunto de obras que repõem o bandeirante no centro da história brasileira. Ele certamente se apresenta, por inesperado que possa parecer quando se considera essa obra no conjunto de um projeto modernista bastante inovador, como mais uma das contribuições que inflaram a figura do bandeirante tão preciosa aos setores mais conservadores da época. Mas o faz infligindo à mitologia bandeirante uma clivagem. Se nas diversas perspectivas que retomam o bandeirante sua imagem é manejada fundamentalmente para explicar a psicogênese do tipo paulista que lhe teria permitido atravessar a história da colonização com tamanha centralidade chegando a se cogitar que a ele se deve o desenho mesmo do território brasileiro, de dimensões continentais, em Pau Brasil ele permite uma articulação diversa: o 
gesto decisivo de apagamento da herança lusitana da cultura brasileira, e com ela da dimensão de heteronomia envolvida na condição de colônia de que seu passado recente lhe rememorava. Sua retomada não implica a reivindicação de uma supremacia paulista, tampouco busca dar coesão social a um conjunto heterogêneo em situaçôes de conflito, inclusive armado, como aconteceu nos momentos de arroubos separatistas, ou forjar o enraizamento social a uma grupo político em detrimento de outros em um contexto de vertiginosa transformação, todas elas iniciativas bastante estranhas à tônica geral da poesia oswaldiana.

A evocação do mito bandeirante lhe fornece instrumentos para uma empreitada muito mais preciosa: Pau Brasil empreende o forjamento de uma figura originária alternativa à do colonizador português, e com isso permite que este seja simplesmente suprimido da história de um Brasil que se descobre em suas páginas. Precisamente na medida em que esse mito, apresentado quase como produto da terra, substitui um dos troncos da cultura brasileira, a herança lusitana, é que se constitui o gesto de apagamento do próprio fenômeno da colonização. ${ }^{8}$

Se o bandeirante, diversamente apropriado, ganha tamanha envergadura em um momento de forte valorização da nação, em que se multiplicam projetos não só de desenvolvimento nacional, mas, fundamentalmente no âmbito do modernismo, de criação da nação, a se plasmar em termos de cultura, a figura do sertanista paulista resolve um problema fundamental: se, para construir uma estética genuinamente nacional, é necessário acessar o passado na busca de uma substância cultural que lhe dê autenticidade, esse passado pode ser cindido de sua dimensão de heteronomia inalienável de sua condição de colônia.

O amor a São Paulo, que atravessa suas páginas, é declarado inequivocamente ao final do livro, quando da chegada da embarcação a Santos. Ali o poema posiciona São Paulo, lugar da vanguarda nacional, no epicentro do Brasil e como lugar visado pela jornada de Pau Brasil. Toda a travessia do poema, que percorre caminhos desbravados em parte pelos bandeirantes, passando por Minas Gerais, Bahia, Pernambuco e Rio de Janeiro, visa sua chegada a São Paulo: rochedos de São Paulo

Everest da Atlântida Vanguarda calcinada do Brasil Ponto geocêntrico eriçado

Contras as escarpas das ondas

Do Amazonas

Poleiro de Gago Coutinho.

[Andrade, (1925) 2003, p. 195, grifos meus.]

São Paulo aparece nesse poema em associação a um símbolo de grandeza, o Everest. Essa associação é acompanhada de outra, que lhe é correlata: a sátira do português, incontáveis vezes presente no livro, que aqui se apresenta na tematização da figura de Gago Coutinho, piloto lusitano que, ao lado de Sacadura Cabral, acabava de entrar para a história como o primeiro aviador a atravessar o Atlântico Sul, em uma espécie de atualização da jornada do conquistador do século XVI. O poema o compara a uma galinha, ave cujo voo não ultrapassa um metro de altura, visto que apresenta o Everest paulista como seu poleiro.

Esse gesto em alguma medida repõe o mote inicial que sequestrara aos portugueses o gesto da descoberta. Nesse sentido, os paulistas são considerados um povo "autodescoberto". Como quem separa o joio do trigo, essa trama diferencia herança cultural e passado colonial, e na mitologia que cerca os sertanistas, na sua maior parte portugueses ou descendentes imediatos deles, prescinde de lidar com os constrangimentos de reconhecer tal dimensão da história brasileira. Forma curiosa, mas bastante rentável aos projetos nacionais, inclusive aos estéticos, de fabricar o nosso esquecimento.

\section{Notas}

1 A data entre colchetes é a da primeira publicação do livro. Fora dos colchetes está a data da edição utilizada neste artigo.

2 Segundo o célebre genealogista do século XIX Luís Gonzaga da Silva Leme, Fernão Dias era filho de Pedro Dias Paes Leme (paulista, filho de Fernando Dias, natural de Abrantes, Portugal, e de Lucrecia Leme, 
natural de São Paulo, que por sua vez era filha de Pedro Leme, natural de São Vicente, onde deve ter nascido entre 1560 e 1570) e de Maria Leite paulista, filha de Pachoal Leite Furtado, dos Açores, e Izabel do Prado (Leme, 1904, p. 450). Antonio Raposo Tavares era português; Manuel Preto e Domingos Jorge Velho eram filhos de portugueses; e mesmo João Ramalho, que, se não foi exatamente um bandeirante, é frequentemente evocado para ilustrar o espírito de adoção das terras de Piratininga como seu novo solo natal, era português (Leme, 1904).

3 Na carta, Fernão Dias comunica sua intenção de atender à solicitação que lhe chega por carta régia de dom Afonso VI e comunica a composição da expedição (Barreiros, 1979, pp. 23-27).

4 As providências comemorativas endossam essa história monumental protagonizada pelos paulistas. Nesse âmbito foi prevista a construção dos quatro marcos comemorativos no Caminho do Mar: o Cruzeiro Quinhentista, Tropas e Circulação de Produtos, o Rancho da Maioridade e o Rancho de Paranapiacaba, "acentuando a transposição da inóspita Serra do Mar como símbolo da intrepidez, da coragem, da sobranceria e da altivez dos paulistas. [...] Os marcos cronológicos desta espécie de narrativa visual, incrustrada em um obstáculo natural, catalisavam todas as façanhas paulistas num heroísmo de alcance nacional. Nesse aspecto, o bandeirismo ofereceu, de fato, a primeira e mais epidérmica solução simbólica para o problema da lealdade dividida, que se devia, ao mesmo tempo, a São Paulo e à nação brasileira" (Saliba, 2004, p. 574).

5 O próprio capítulo "Bandeiras", de Paulística, pode ser lido como uma tentativa de resposta a essa pergunta que, aliás, consta de seu parágrafo inicial.

6 Antonio Prado é considerado por Saes o caso paradigmático: "Antonio da Silva Prado (1840-1929) talvez seja o caso exemplar de empresário associado à noção de capital cafeeiro. Formado em Direito pela Faculdade do largo de São Francisco em 1861, voltou-se, de início, à administração das propriedades rurais da família. Junto com seu pai - Martinho Prado - e seu irmão - Marinho Prado Júnior ou Martinico Prado - foi proprietário de algumas das maiores fazendas de café de São Paulo, primeiro na região de Limeira e depois de Ribeirão Preto. Porém, dos anos $70 \mathrm{em}$ diante seus interesses econômicos pendem claramente para as atividades urbanas. Participou, como acionista ou dirigente, de estradas de ferro de São Paulo como a Paulista e a Mogiana. Em particular, foi presidente da Companhia Paulista de Estradas de Ferro por mais de vinte anos. Nos anos
80 foi acionista da Companhia de Carris de Ferro de São Paulo (bondes a burro na capital). Importante acionista do banco do Comércio e Indústria de São Paulo (fundado em 1889), foi seu presidente por mais de trinta anos. Durante o Encilhamento, fundou a Companhia Central Paulista que, finda a euforia, foi transformada na Casa Prado Chaves \& Cia., importante comissária de café que, inclusive, participou das transações do programa de defesa do café na Primeira República. Foi fundador e dirigente da Vidraria Santa Marina, que fornecia garrafas para cervejarias (em particular para a Antarctica), além de outros tipos de vidros. Participou da formação dos frigoríficos de Santos e de Barretos junto com Alexandre Siciliano (da Companhia Mecânica e Importadora) e de Roberto Simonsen (entre 1910 e 1917). Além de manter participação em outras empresas (com as de energia de algumas localidades do interior), Antonio Prado teve intensa atividade política. Foi ministro no Império, parlamentar tanto no Império quanto na República e prefeito da Cidade de São Paulo entre 1899 e 1910. Estes dados não deixam qualquer dúvida sobre a natureza predominante dos negócios de Antonio Prado, embora o ponto de partida de sua riqueza tivesse sido a fazenda de café" (Saes, 2004, pp. 241-242).

7 Isso sem considerar aqueles que não descendem dos exploradores sertanistas, como é o caso dos Prado. Quem o explicita é Katia Abud: "Quanto aos fazendeiros das famílias da elite, sua origem não ia, na maior parte das vezes, além da segunda metade do século XVIII e, puxado o fio da meada da dinastia, achava-se um tropeiro, um comerciante, um traficante de escravos que, enriquecidos pelos negócios, tinham aplicado suas rendas na propriedade fundiária. [...] Caso mais conhecido é a da origem da família Prado, português que chegou a São Paulo logo no início do século XVIII, como mais um que procurava sucesso nas atividades mercantis que as condiçōes peculiares da cidade propiciavam. Foram seus descendentes que amealharam fortuna, um século depois da chegada do primeiro Prado a São Paulo. Antonio da Silva Prado, comerciante de gado e arrematante de impostos, amealhou com suas atividades mercantis um considerável cabedal que posteriormente transformou os Prado em grandes proprietários de terra” (Abud, 1985, p.122).

8 Em minha tese de doutorado investiguei as relaçôes entre as perspectivas de modernidade implicadas nos modernismos brasileiro e português, perscrutando as razōes de sua mútua negação estabelecida em ambos os cenários culturais. Para mais detalhes, ver Teixeira (2009). 


\section{BIBLIOGRAFIA}

ABUD, Katia Maria. (1985), O sangue itimorato $e$ as nobilissimas tradiçôes - a construção de um simbolo paulista: o bandeirante. Tese de doutorado. Departamento de História da Faculdade de Filosofia, Letras e Ciências Humanas da Universidade de São Paulo.

ADDUCI, Cássia Chrispiniano. (2000), A 'Pátria paulista': o separatismo como resposta à crise flnal do Império brasileiro. São Paulo, Arquivo do Estado/Imprensa Oficial do Estado de São Paulo.

ANDRADE, Oswald. ([1925] 2003), Pau Brasil, in Obras completas, São Paulo, Globo.

BARREIROS, Eduardo Canabrava. (1979), Roteiro das Esmeraldas: a bandeira de Fernão Dias Pais. Rio de Janeiro/Brasília, José Olympio/INL.

BERRIEL, Carlos Eduardo Ornelas. (2000), Tietê, Tejo, Sena: a obra de Paulo Prado. Campinas, SP, Papirus.

CALIL, Carlos Augusto. (2004), "Um brasileiro de São Paulo", in Paulo Prado, Paulística etc. 4. ed. revista e ampliada. São Paulo, Companhia das Letras.

CAMPOS, Haroldo de. (2003), "Uma poética da radicalidade", in Oswald de Andrade, Pau Brasil, 2. ed., São Paulo, Globo.

CAMPOS, Haroldo de. (2004), "Miramar na mira", in Oswald de Andrade, Memórias sentimentais de João Miramar, São Paulo, Globo.

CAPELATO, Maria Helena R. (1985), Os arautos do liberalismo. São Paulo, Brasiliense.

CARONE, Edgard. (1969), A Primeira República. São Paulo, Difel.

COSTA, Emília Viotti da. (2010), Da Monarquia à República. 4. ed. São Paulo, Editora Unesp.

CORTESĀO, Jaime. (1961), “A maior bandeira do maior bandeirante". Revista de História, 22 (45): 3-27.

ELLIS JR., Alfredo. (1936), Os primeiros troncos paulistas. 2. ed. São Paulo, Editora Nacional.

FERRETTI, Danilo J. Zioni. (2008), “O uso político do passado bandeirante: o debate entre Oliveira Vianna e Alfredo Ellis Jr. (19201926)". Estudos Históricos, 21 (41): 59-78.
FONSECA, Maria Augusta. (2007), Oswald de Andrade: biografia. 2. ed. São Paulo, Globo.

GAUDEZ, Florent. (1997), Pour une socio-anthropologie du texte littéraire. Paris, L'Harmattan.

GLEZER, Raquel. (1992), Chão de terra: um estudo sobre São Paulo colonial. Tese de livre-docência. Departamento de História da Faculdade de Filosofia, Letras e Ciências Humanas da Universidade de São Paulo.

LEENHARDT, Jacques. (1998), "Uma sociologia das obras de arte é necessária e possível?". Tempo Social, 10 (2): 101-111.

LEME, Luís Gonzaga da Silva. (1904), Genealogia paulistana. São Paulo, Duprat \& Cia., vol. 2.

LOVE, Joseph. (1982), A locomotiva: São Paulo na federação brasileira (1889-1937). Rio de Janeiro, Paz e Terra.

MACHADO, Antonio de Alcântara. ([1929] 2006), Vida e morte do bandeirante. São Paulo, Imprensa Oficial do Estado de São Paulo.

MAKINO, Miyoko. (2002-2003), "Ornamentação do Museu Paulista para o Primeiro Centenário: construção de identidade nacional na década de 1920". Anais do Museu Paulista, 10/11: 167-195.

MARTINS, José de Souza. (2004), "O migrante brasileiro na São Paulo estrangeira”, in P. Porta, História da cidade de São Paulo: a cidade na primeira metade do século XX (1890-1954), São Paulo, Paz e Terra.

MILLIET, Sérgio. (2006), "Apresentação", in Antonio de Alcântara Machado, Vida e morte do bandeirante. São Paulo, Imprensa Oficial do Estado de São Paulo.

MONTEIRO, John Manuel. (1994), Negros da terra: indios e bandeirantes nas origens de São Paulo. São Paulo, Companhia das Letras.

MORSE, Richard. (1970), Formação histórica de São Paulo (de comunidade à metrópole). São Paulo, Difel.

MOTTA, Marly Silva da. (1992), A nação faz 100 anos: a questão nacional no centenário da independência. Rio de Janeiro, Editora FGV.

PÉQUIGNOT, Bruno. (1993), Pour une sociologie esthétique. Paris, L'Harmattan.

PRADO, Paulo. ([1925] 2004), Paulistica etc. 4. ed. revista e ampliada por Carlos Augusto Calil. São Paulo, Companhia das Letras. 
QUEIROZ, Maria Isaura Pereira de. (1992), "Ufanismo paulista: vicissitudes de um imaginário”. Revista Usp, 13: 78-87.

RICARDO, Cassiano. (1941), "O Estado Novo e seu sentido bandeirante". Cultura Política, 1 (1): 110-132.

SAES, Flávio. (2004), "São Paulo republicana: vida econômica", in Paula Porta, História da cidade de São Paulo: a cidade na primeira metade do século XX (1890-1954), São Paulo, Paz e Terra.

SALIBA, Elias Thomé. (2004), "Histórias, memórias, tramas e dramas da identidade paulistana", in Paula Porta, História da cidade de São Paulo: a cidade na primeira metade do século XX (1890-1954), São Paulo, Paz e Terra.

SEVCENKO, Nicolau. (1992), Orpheu extático na metrópole (São Paulo: sociedade e cultura nos frementes anos 20). 3. reimp. São Paulo, Companhia das Letras.

. (1998), "O prelúdio republicano: astúcias da ordem e ilusões do progresso", in (org.), História da vida privada no Brasil. Vol. 3: República: da Belle Époque à Era do Rádio, São Paulo, Companhia das Letras, pp. 7-48.

SOUZA, Laura de Mello e. (2000), "Vícios, virtudes e sentimento regional: São Paulo, da lenda negra à lenda áurea”. Revista de História, 142143: 261-276.

TEIXEIRA, Ana Lúcia. (2009), Modernidades em confronto: as literaturas modernistas brasileira e portuguesa. Tese de doutorado. Departamento de Sociologia da Faculdade de Filosofia, Letras e Ciências Humanas da Universidade de São Paulo. 


\section{A LETRA E O MITO: CONTRIBUIÇŌES DE PAU BRASIL PARA A CONSAGRAÇÃO BANDEIRANTE NOS ANOS DE 1920}

\section{Ana Lúcia Teixeira}

Palavras-chave: Pau Brasil; Oswald de Andrade; Modernismo paulista; Bandeirante.

O objetivo deste artigo é perscrutar a contribuição dada por Pau Brasil, de Oswald de Andrade, à mitologia bandeirante consolidada no período, ampliando o leque dos usos políticos que se fizeram dessa figura mitológica. Trata-se de inserir essa obra emblemática da fase heroica do modernismo paulista, reconhecidamente vanguardista e progressista, num debate cujo sentido geral era o de fornecer uma explicação histórica para a dianteira econômica de São Paulo e, com isso, justificar suas pretensóes de supremacia política. No entanto, este artigo busca delimitar uma clivagem constituída por Pau Brasil no ideário bandeirante do momento: distanciando-se da pretensão de sobrepujar o restante da nação, num gesto de apagamento da herança cultural portuguesa Pau Brasil constrói a figura do bandeirante para substituir o colonizador nas origens culturais brasileiras.

\section{THE LETTER AND THE MYTH: CONTRIBUTIONS OF PAU BRASIL TO THE BANDEIRANTE CONSECRATION IN THE 1920'S}

\section{Ana Lúcia Teixeira}

Keywords: Pau Brasil; Oswald de Andrade; Sao Paulo's modernism; Bandeirante.

The purpose of the article is to scrutinize the contribution of Oswald de Andrade's book Pau Brasil to the mythology of the bandeirante, which was consolidated in the period, extending the range of political uses made about such mythological figure. In this sense, the article inserts this emblematic work of the heroic phase of Paulista modernism - admittedly an avant-garde and progressive work - in a debate whose general direction was to provide an historical explanation for the economic strength of Sao Paulo, and thus justify its claims to political supremacy. According to the author, however, Pau Brasil represents a cleavage in the conceptions of the bandeirante, which she seeks to delimit. For her, Pau Brasil distances itself from any kind of claim to overcome the rest of the nation. In a gesture intended to erase the strength attributed to the Portuguese heritage, the book builds the figure of the bandeirante in order to replace the colonizer in the origins of the Brazilian cultural backgrounds.

\section{LE MOT ET LE MYTHE: DES CONTRIBUTIONS DE PAU BRASIL À LA CONSÉCRATION BANDEIRANTE DANS LES ANNÉES 1920}

\section{Ana Lúcia Teixeira}

Mots-clés: Pau Brasil ; Oswald de Andrade; Modernisme pauliste; Bandeirante.

Le but de cet article est d'examiner la contribution apportée par Pau Brasil, l'œuvre de Oswald de Andrade, à la mythologie bandeirante consolidée au cours des années 1920 et qui a amplifié l'éventail des usages politiques qui ont été fait de cette représentation mythologique. Il s'agit d'insérer cette œuvre emblématique de la phase héroïque du modernisme pauliste, reconnue comme étant d'avant-garde et progressiste, dans un débat dont le but était de fournir une explication historique à l'avancée économique de São Paulo et de justifier, ainsi, ses prétentions à la suprématie politique. Cet article tente, néanmoins, de définir un clivage constitué par Pau Brasil dans l'idéal bandeirante de l'époque : en s'écartant d'une revendication de la suprématie politique de São Paulo, et dans un geste d'effacement de l'héritage culturel portugais, Pau Brasil construit le mythe du bandeirante pour remplacer le colonisateur dans les origines culturelles brésiliennes. 